\title{
Research on Cloud Enterprise Resource Integration and Scheduling Technology Based on Mixed Set Programming
}

\author{
Wei SHI, Dunbing TANG*, Ping ZOU
}

\begin{abstract}
With the development of Industry 4.0 and intelligent manufacturing, the production of a complex product requires the collaboration of multiple companies. Aiming at the problems of incompatibility of a large number of heterogeneous manufacturing resource interfaces and collaborative scheduling of manufacturing resources between enterprises, based on metadata and ontology modeling methods, a standardized model description of manufacturing resources is realized. By using Mixed Set Programming methods, we proposed a strategy for collaborative scheduling of manufacturing resources between enterprises. The verification results of enterprise application examples show that the model and scheduling strategy proposed in this paper are effective for the collaborative scheduling of resources between enterprises, the allocation of manufacturing resources between enterprises can be optimized, and the efficiency of collaboration between enterprises can be improved. The model and scheduling strategy could be applied to promote the optimal allocation of manufacturing resources
\end{abstract}

Keywords: Cloud Manufacturing; Cloud Manufacturing Service Platform; Manufacturing Resources; Ontology Modeling

\section{INTRODUCTION}

With the development of a new generation of information technology represented by cloud computing, big data, and the Internet of Things, Industry 4.0, smart manufacturing, and cloud manufacturing [2-4] drive the deep interconnection of the entire industry, the entire industry chain, and the entire value chain. Moreover, the optimal allocation of production and service resources can be promoted, and the reengineering of the manufacturing system and service system can be promoted. It has begun to play a core supporting role in the current industrial digital transformation process [5-9]. Industry 4.0 makes the intelligent production model shift from mass customization to individual customization, and single-piece and smallbatch customization production would become the mainstream [10, 11]. As personalized customization has gradually become the strategic direction of the entire manufacturing enterprise, the "customer-centric" flexible production concept is deeply rooted in the hearts of the people. Traditional manufacturing companies are facing many challenges, such as the rapid increase in product types and personalized requirements, frequent changes in the number of orders and sources of demand, and the urgent need to improve the efficiency of small-batch production. The sharing of manufacturing data based on the supply chain between the supplier and the demander is particularly important. Upstream companies master the demand information of downstream companies. Downstream companies provide upstream companies with production plans and execution information. As a new service-oriented manufacturing model, cloud manufacturing has developed rapidly in recent years. Under the cloud manufacturing model, various manufacturing companies can release manufacturing resources, software resources, production capabilities, design capabilities and other resources through the cloud manufacturing service platform. Manufacturing enterprises can use the services provided by the cloud manufacturing platform to complete their tasks in the design, production, planning, sales and other links, and flexibly manufacture products to serve users, thereby improving their market competitiveness.
Aiming at the problem of collaborative scheduling of resources between enterprises under the cloud manufacturing model, based on metadata and ontology modeling methods, a mechanism for collaborative scheduling of resources between enterprises is proposed. On the basis of proposing resource capacity model and order demand task model [12, 13], it comprehensively considers multiple constraints based on the hybrid set planning method. It can provide supply and demand companies in the supply chain with a collaborative production plan with small order delays and low costs.

\section{RELATED WORKS \\ 2.1 Research Status}

Based on the cloud manufacturing service platform, both small and medium-sized enterprises (SME) and large and medium-sized enterprises (LME) can establish their own virtual enterprises (VE) [14-18] in the cloud, and build their own-led virtual enterprise circle with manufacturing tasks as the link, as shown in Fig. 1. Virtual organizations share their own resources under certain rules, and the production collaboration among members of the organization can achieve complementary advantages and shared risks. This can not only adapt to global competition, but also meet the individual needs of consumers and enable members to develop rapidly.

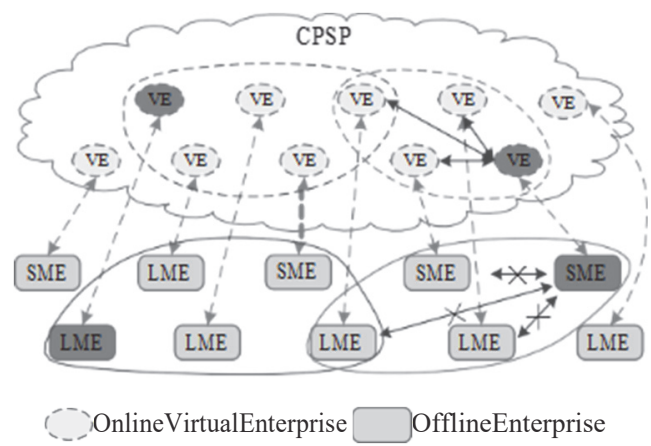

Figure 1 VEC diagram on cloud manufacturing service platform

Based on online collaborative production, the enterprise breaks the barriers of information exchange 
between enterprises, and builds a dynamic virtual enterprise circle alliance led by the enterprise and subordinate to the collaborative production enterprise. Taking production orders as the main line can open up the collaborative production information flow between enterprises and help enterprises carry out closed-loop management of the entire product life cycle of design, production, manufacturing, warehousing and sales. The end-to-end process from collaborative research and development to collaborative production and from order to delivery can be realized.

When an enterprise builds its own virtual enterprise in the cloud, it needs to virtualize and map the enterprise's manufacturing resources and capabilities to the cloud manufacturing service platform [19-21]. Faced with the problems of incompatible interfaces of a large number of heterogeneous manufacturing resources and inconsistent data formats, how to achieve the standardized description of manufacturing resources is the key to the efficient operation of the cloud manufacturing service platform. In addition, after manufacturing resources and resource data of supply and demand enterprises are integrated into the cloud manufacturing service platform, how to provide suppliers and their suppliers with a coordinated resource scheduling plan with small order delays, low costs, and balanced capacity utilization based on the platform is also the main topic of this paper.

\subsection{Problem Description}

Collaborative production resource scheduling between enterprises in the cloud manufacturing environment uses the sales orders of the demanding enterprises as the input source to coordinate the orderly production of each enterprise and each workshop, as shown in Fig. 2. Tasks are reasonably allocated to various cooperative enterprises to ensure the smooth coordination of the production processes of multiple enterprises.

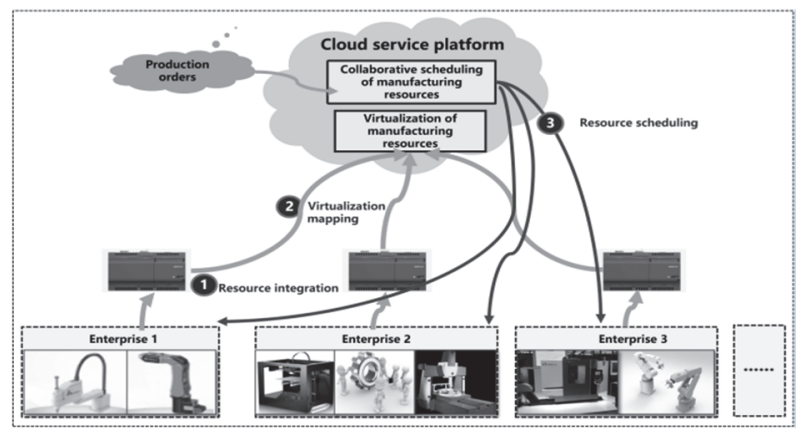

Figure 2 The application mode of resource scheduling on cloud manufacturing service platform

This application model virtualizes manufacturing resources as a service, which can facilitate users to use production resources based on the cloud. The main workflow is as follows.

(1) Through the industrial gateway connection, the enterprise's manufacturing resources and capabilities are integrated into the cloud manufacturing service platform. On the basis of virtualization as a service, a cloud manufacturing resource pool is formed.

(2) Through the cloud manufacturing service platform, demand-side enterprises can issue orders.
(3) Product supply companies obtain orders based on the cloud manufacturing service platform. They combine the virtual enterprise business circle to intelligently schedule manufacturing resources and capabilities to form a self-made production plan, a material purchase plan and an outsourcing plan. Then, they can issue the self-made plan to the internal manufacturing execution system of the enterprise, and republish the procurement and outsourcing plan to the cloud platform to carry out interactive work with the supplier.

(4) The supplier completes the product assembly and delivers it after the experimental inspection.

Different from the workshop-level resource scheduling, the collaborative production resource scheduling between enterprises in the cloud manufacturing environment is a strategic-level scheduling of multiple collaborative production companies. No specific equipment resources and production time points are specified, and only the number of daily working hours occupied by the released professional units is provided by the enterprise.

\section{RESEARCH METHODOLOGY \\ 3.1 Model Settings}

The symbols involved in the techniques and methods in this paper are summarized as shown in Tab. 1. The data class is named in all English capitals, the attribute names in the data class are attribute plus class, and the first letter of the collection is capitalized.

\begin{tabular}{|c|c|}
\hline Symbol & Description \\
\hline$M A X D E L A Y$ & Maximum tardiness time constant \\
\hline$P L$ & Scheduling plan collection \\
\hline$p l$ & Dispatch plan variable, $p l \in P L$ \\
\hline SLOT & Scheduled date collection \\
\hline$d$ & Schedule date variable, $d \in S L O T$ \\
\hline ORDER & Collection of all orders \\
\hline$o$ & Order variable, $o \in O R D E R$ \\
\hline$J O B$ & Collection of all artifacts \\
\hline$j$ & Workpiece variable, $j \in J O B$ \\
\hline TASK & All tasks collection \\
\hline$t$ & Task variable, $t \in T A S K$ \\
\hline PROVIDER & The collection of all companies in the supply chain \\
\hline$v$ & Enterprise variable, $v \in P R O V I D E R$ \\
\hline$G R S$ & Collection of all professional units \\
\hline$g$ & Professional unit, $g \in G R S$ \\
\hline$T O_{o}$ & Task collection for order $o$ \\
\hline $\mathrm{JO}_{\mathrm{o}}$ & Collection of artifacts for order $O$ \\
\hline$T J_{j}$ & Task set of artifact $j$ \\
\hline$T G_{g}$ & Professional unit $g$ actually undertakes a set of tasks \\
\hline$G r T_{t}$ & The actual production professional unit set of task $t$ \\
\hline$V T_{t}$ & The actual production enterprise set of task $t$ \\
\hline$c G D_{d, g}$ & $\begin{array}{l}\text { Available working hours of professional unit } g \text { on date } \\
d\end{array}$ \\
\hline $\operatorname{PrecGrTG}_{t, g}$ & $\begin{array}{l}\text { Professional unit } g \text {, a collection of professional units } \\
\text { that are the successor to the production task } t\end{array}$ \\
\hline SuccGrTG $G_{t, g}$ & $\begin{array}{l}\text { Professional unit } g \text { production task } t \text { predecessor task } \\
\text { professional unit collection }\end{array}$ \\
\hline$i G_{g}$ & Working range of professional unit $g$ \\
\hline$t m T G_{g, t}$ & The production time of task $t$ on professional unit $g$ \\
\hline$q t y T G_{g, t}$ & The production quantity of task $t$ on professional unit $g$ \\
\hline $\operatorname{div} T G_{g, t}$ & The production strategy of task $t$ on professional unit $g$ \\
\hline Batch $_{g, t}$ & Batch collection of task $t$ on professional unit $g$ \\
\hline $\operatorname{SuccTV} V_{v, t}$ & Task $t$ is set in the successor enterprise of enterprise $v$ \\
\hline
\end{tabular}




\subsection{Overall Architecture}

\subsubsection{The Integrated Framework of manufacturing Resource Access Cloud Platform}

The integrated framework of cloud manufacturing service platform manufacturing resource access is shown in Fig. 3. It includes the resource layer, access layer, and platform layer. According to the function of manufacturing resources in the entire manufacturing life cycle, the resource layer divides manufacturing resources into three categories: hard manufacturing resources, soft manufacturing resources and manufacturing capabilities. The access layer integrates manufacturing resources and manufacturing capabilities into the cloud manufacturing service platform through data preprocessing, data caching/storage, and data analysis on the edge side, with the help of dedicated networks, Internet of Things, sensor networks, Ethernet and other transmission networks.

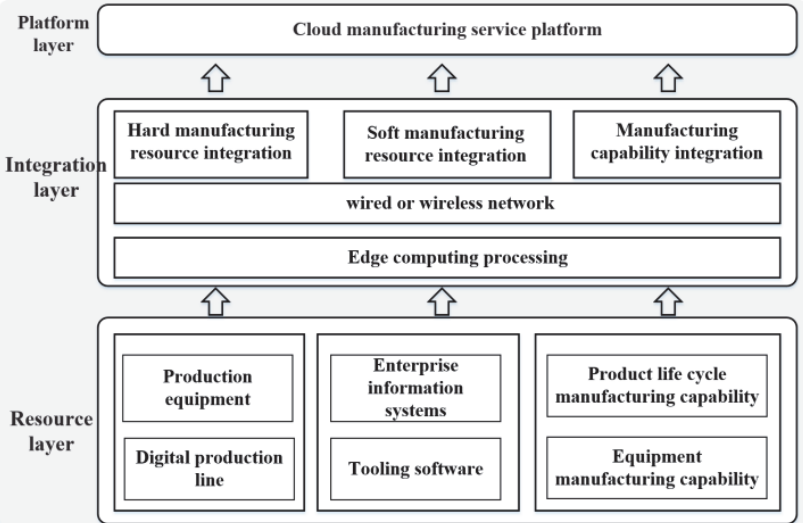

Figure 3 The Integration framework of manufacturing resource access for cloud manufacturing service platform

According to the application requirements of business resources in the full life cycle of manufacturing activities, the integrated hard manufacturing resources in the cloud manufacturing service platform generally include: (1) Basic information resources, including cloud computing centers, data centers, computing equipment, etc. Its integration should enable the management and invocation of cloud resources, such as viewing resource usage and resource allocation. (2) Manufacturing equipment, including machining equipment, electrical equipment, environmental testing equipment, etc. Its integration should enable the management of cloud device manufacturing capabilities and the collection of device status information. (3) Digital production line, including machine-added digital production line, welding digital production line resource management and status information collection.

The integrated soft manufacturing resources of the cloud manufacturing service platform generally include the following: (1) Enterprise information management system and production management system. (2) Tool software and industrial application software. (3) Knowledge model library, including public model library, fault diagnosis model and rule library, etc.

The integrated manufacturing capabilities in the cloud manufacturing service platform are classified according to the manufacturing life cycle activities, and generally include manufacturing capabilities such as design capabilities, production and processing capabilities, and supply capabilities.

The process of cloud manufacturing service platform resource access integration is shown in Fig. 4. For intelligent controllers, sensors, instruments, etc., data collection is realized through intelligent gateways or field buses. For data stored in different places and from multisource heterogeneous systems such as ERP/PDM, the acquisition, storage and application of data are realized through heterogeneous data adaptive acquisition tools.

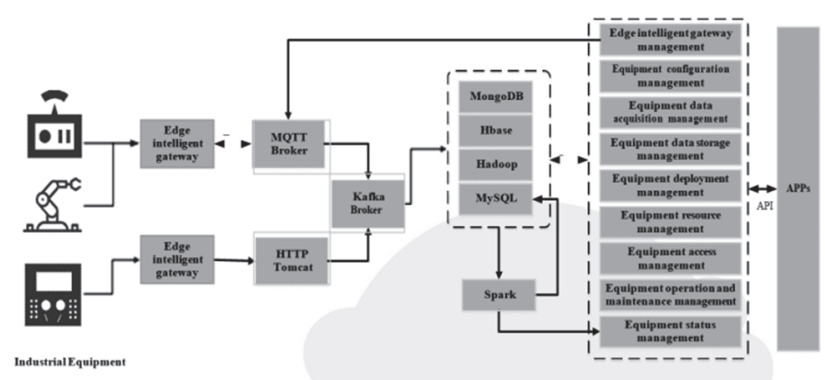

Figure 4 The Integration process of manufacturing resource access for cloud manufacturing service platform

\subsubsection{Standardized Description Model of Enterprise Manufacturing Resources}

Enterprise manufacturing resources in the cloud manufacturing environment are mapped into mathematical models using metadata and ontology service technology [22-26], as shown in Fig. 5. Metadata refers to descriptive data for standardized description, positioning and management of manufacturing resource attributes to promote the full sharing of manufacturing resources.

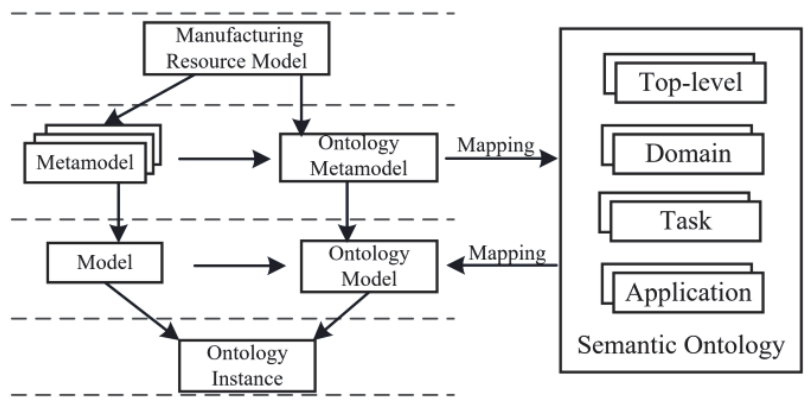

Figure $\mathbf{5}$ The technical implementation scheme of metadata ontology representation method on manufacturing resources

Ontology service adds formal semantic information to resource representation, enabling resources to be quickly discovered and applied in a complex networked environment. OWL-S (Web Ontology Language for Service) is an ontology service description language based on the Semantic Web. It can start from ServiceProfile (describe the basic information, functional attributes and constraint information of the service), ProcessModel (describe the process information of the service) and ServiceGrounding (describe the service interface information) to describe the ontology service in three aspects.

Based on the above definition of metadata, the manufacturing resource metadata $\mathrm{M}$ consists of a set of 
metadata elements $\mathrm{Mi}$ that describe the attributes of the manufacturing resource.

Each element represents the attribute of the manufacturing resource, namely $\forall M_{i} \in M, M_{i} \in A$ where $A$ is the attribute set of the manufacturing resource. The metadata model can be expressed as $M=\sum_{i=1}^{n} M_{i}$, where $n$ is the number of attributes of the manufacturing resource.

Manufacturing resources in inter-enterprise resource scheduling are represented by specialized units. The professional unit is the smallest scheduling resource in enterprise resource scheduling, which represents the sum of the same type of manufacturing equipment or capabilities in an enterprise. The granularity of specialized units is coarser than that of traditional workshop-level work centers or equipment, and their capabilities are the accumulation of equipment capabilities of the same resource type. The supply resource model considers the company's ability to undertake and the quotation constraints, as well as the time and cost constraints when parts are transferred between companies.

The metadata ontology model of the professional unit can be described as:

g_MO $=\left(g_{-}\right.$ID,$g \_$BaseInfo, g_CapaInfo, TransactionInfo, g_StateInfo), and $g_{-} I D$ is the unique identifier of the professional unit.

o_TaskInfo $=(j T, p c T$, SuccT, PrecT, GroT, V0T) is the basic information of professional units. Among them, $i c G$ is the minimum amount to be accepted, $x c G$ is the maximum amount to be accepted, $u p G$ is the unit man-hour quotation, $r t G$ is the resource type, $v G$ is the name of the company to which it belongs, and $a d V$ is the address of the company.

$g$ CapaInfo $=(c G C, s 1 G C, s 2 G C, p G C)$ is the professional unit capability information. Among them, $c G C$ is the daily working hour capacity, $s l G C$ is the start date, $s 2 G C$ is the end date, and $p G C$ is the priority.

$g \_$TransactionInfo $=(v 1, v 2, d s V V, \operatorname{tm} V V, c s V V)$ is the transaction information of the professional unit. Among them, $v 1$ is the origin enterprise, $v 2$ is the destination enterprise, $d s V V$ is the distance between enterprises, $t m V V$ is the transportation time between enterprises, and $c s V V$ is the transportation cost between enterprises.

$g$ StateInfo is used to describe the starting and stopping state, load situation, current task list and other information of the professional unit.

Define $g$ as an instance variable of the professional unit model. The metadata ontology model of order requirements is:

$o_{-} M O=\left(o_{-} I D, \quad o_{-}\right.$BaseInfo, o_ProductInfo,

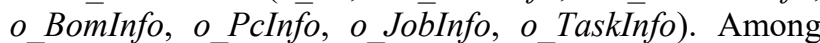
them, $o \_I D$ is the unique identifier of the order.

$o_{\text {BaseInfo }}=($ qtyO $, s 1 O, s 2 O, p t O)$ is the basic information of the order. Among them, qty $O$ is the required quantity, $s 1 O$ is the earliest start date, $s 2 O$ is the latest delivery date, and $p t O$ is the order priority.

$o$ ProductInfo $=(n m P, t p P)$ is the basic product information. Among them, $n m P$ is the product name, and tpP is production or purchase.

$o_{-}$BomInfo $=(p B M$, prtBM, $r B M)$ is the product structure tree information. Among them, $p B M$ represents the product $\mathrm{BOM}$, prtBM is the parent product $\mathrm{BOM}$, and $r B M$ is the parent product proportional relationship.

$o \_P c I n f o=(p P C, n m P C, s q P C, r t P C, u t P C)$ is the process information. Among them, $p P C$ is the corresponding product, $n m P C$ is the process name, $s q P C$ is the production sequence, $r t P C$ is the resource type, and $u t P C$ is the standard working hours.

$o \_J o b I n f o=(o J, p r J, q t y J, p J)$ is the job information. Among them, $o J$ is the order corresponding to the workpiece, $p r J$ is the parent workpiece, qtyJ is the production quantity, and $p J$ is the product corresponding to the workpiece.

$o_{-}$TaskInfo $=(j T, p c T$, SuccT, PrecT, GroT, V0T $)$ is task information. Among them, $j T$ is the work piece corresponding to the task, $p c T$ is the process of the task, SuccT is the successor task set, PrecT is the predecessor task set, GrOT is the professional unit set that can undertake the task, and VOT is the supplyable enterprise set.

Define $o$ as an instance variable of the order demand model, $j$ as a workpiece information variable, and $t$ as a task information variable.

\subsection{Enterprise Scheduling Strategy Based on Mixed Set Programming}

In the cloud manufacturing environment, the demandside and supplier-side enterprise resource system scheduling is an NP-Hard combinatorial optimization scheduling problem [27]. In this paper, a hybrid set programming method and branch cutting algorithm are used to solve the problem.

\subsubsection{Mixed Set Planning}

Mixed Set Programming (MSP) is a logic solution system that uses first-order logical sum and set reasoning as the algorithm framework in mixed domains (real numbers, integers, Boolean values, indexes, and sets). Natural Constraint Language (NCL) [28] is an intelligent description language for business modeling and problem solving that integrates logic, optimization algorithms, and solving rules. NCL uses hybrid ensemble programming as the core of the algorithm. Through the joint reasoning of the network relationship between constraints, the solution space of the combined optimization problem is cut rationally and effectively, the combined explosion is suppressed, and the problem is solved. The NCL solution system is based on the principle of constraint cutting and depth-first search, and its solution framework is shown in Fig. 6.

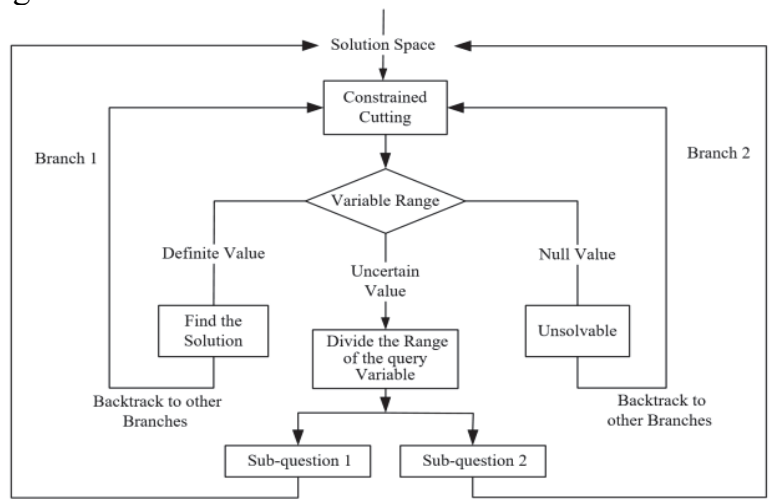

Figure 6 The diagram of algorithm framework 
First, try to use business constraints to cut the solution space. Whenever the cutting process is terminated, if there is a query variable whose range is not a unit set, the branch solution mechanism would be activated. The branching method divides the range of some variables into two through heuristic rules (minimum slackness, convexity principle, minimum regret, greedy method, etc.). The question becomes a sub-question corresponding to the two sub-domains. Because the secondary division of all variable ranges is finite, with the advancement of cutting and branching, the system would surely find a solution or prove that there is no solution to each sub-problem. In the case of no solution, the system would backtrack to other branches to solve. If the solution found is the optimal solution, iterative optimization is no longer performed, otherwise, the next step of iterative optimization is required.

There are three types of variables in the Mixed Set Programming model: original data variables, intermediate variables and decision variables. The original data variables are supply resource variables and order demand variables. The intermediate variables are calculated from the original data variables through modeling. The decision variables are obtained through logical modeling.

The decision variable is the manufacturing resource scheduling plan $p l=(t, g, b, q t y P L, s 1 P L, s 2 P L, t s P L$, $n s P L)$. Among them, $t$ is the task, $g$ is the professional unit, $b$ is the batch, $q t y P L$ is the production quantity, $s 1 P L$ is the planned start date, $s 2 P L$ is the planned completion date, $t s P L$ is the daily production hours, and $n s P L$ is the planned production days.

\subsubsection{Optimize the Target}

The supply chain planning and scheduling model under the cloud manufacturing environment will develop in the direction of multi-objective and multi-constraint. The optimization goals of cross-enterprise collaborative production scheduling are as follows.

$\min \max \left(0, \max s 2 P L_{b, g, t}-s 2 O_{o}\right), t \in T O_{o}$,

$g \in G r T_{t}, b \in$ Batch $_{g, t}, o \in O$

$$
\begin{gathered}
\sum_{g \in G r T_{t}, b \in B a t c h_{g, t}}\left(t s P l_{b, g, t} \times n s P l_{b, g, t} \times u p G_{g}\right)+ \\
+\sum_{t} \sum_{g \in G r T_{t}, g} c s V V_{v G_{g 2}, v G_{g}}, t \in T A S K S G r T G_{g, t}
\end{gathered}
$$

$$
\min \left(\max s 2 P L_{b, g, t}-\min s 1 P L_{1, g, t}\right), t \in T G_{g}
$$

Eq. (1) means minimizing tardiness, and the optimization goal is 0 when it is not tardiness. Eq. (2) means minimizing production costs, including the sum of production costs and the sum of transfer and transportation costs between enterprises. Eq. (3) means minimizing the production span, and the difference between the completion time of the last task undertaken by the professional unit and the start time of the first task is determined. It should be noted that the minimum production span is mainly considered when scheduling production at the workshop level, and the shortest production time and production costs are not considered as optimization targets.

\subsubsection{Constraint Conditions}

The constraints of the cross-enterprise collaborative production scheduling problem include the start and end dates of orders, professional unit production capacity and acceptance volume, product structure and process succession, distance between enterprises, production quantity and working hours. The main constraints are expressed as follows.

$$
\begin{aligned}
& \min s 1 P L_{b, g, t} \geq s 1 O_{o}, t \in T O_{o}, \\
& g \in G r T_{t}, b \in \text { Batch }_{g, t}, o \in O \\
& \max s 2 P L_{b, g, t} \leq s 2 O_{o}+M A X D E L A Y, t \in T O_{o}, \\
& g \in G r T_{t}, b \in \text { Batch }_{g, t}, o \in O
\end{aligned}
$$

Eq. (4) and Eq. (5) indicate that for each order o in the order set ORDER, the task $t$ in the order $o$ is on the professional unit $g$. The production plan start date of batch $b$ cannot be earlier than the earliest start date of the order, and the planned completion date cannot be after the delivery date plus the maximum acceptable delay time.

$$
\begin{gathered}
\sum_{t \in T G_{g}, d \in \text { Batch }_{g, t} d \in\left[s 1 P l_{b, g, t}, s 1 P l_{b, g, t}\right]} t s P l_{b, g, t} \leq c G C_{d, g} \\
i c G_{g} \leq \sum_{t \in T G_{g}, d \in \text { Batch }_{g, t}} q t y P l_{b, g, t} \leq x c G_{g}
\end{gathered}
$$

$\bigcup_{t \in T G_{g}, d \in \text { Batch }_{g, t}}\left[s 1 P L_{b, g, t}, s 2 P L_{b, g, t}\right] \subset i G_{g}$

Eq. (6) indicates that the total daily production hours on each professional unit cannot be greater than the daily working hours capacity of the professional unit. Eq. (7) is that the company has a minimum or maximum limit on the amount of production tasks based on its own cost factors, that is, the number of tasks produced by each professional unit $g$ in the professional unit set GRS cannot be less than the minimum or greater than the maximum. Eq. (8) indicates that the production task undertaken by the professional unit $\mathrm{g}$ needs to be produced within the working range of the professional unit.

$$
\begin{aligned}
& s 1 P L_{b, g, t} \geq s 2 P L_{b, g, t, p r e c}, \\
& t \in T A S K, \mathrm{~g} \in G r T_{t}, \\
& \text { prec } \in \operatorname{PrecTkTV}_{v G g, t}, \\
& b \in \text { Batch }_{g 2, \text { prec }}, \mathrm{g} 2 \in \operatorname{Prec} G r T G_{t, g},
\end{aligned}
$$




$$
\begin{aligned}
& s 1 P L_{1, g, t} \geq s 2 P L O_{b, g 2, \text { prec }}+\mathrm{tmVV}_{v G_{g 2}, v G_{g}}, \\
& t \in T A S K, \mathrm{~g} \in G r T_{t} \text {, } \\
& \text { prec } \in \operatorname{Prec} T_{t}-\operatorname{PrecTkTV} V_{v G, t} \text {, } \\
& b \in \text { Batch }_{g 2, \text { prec }}, g 2 \in \operatorname{PrecGrTG} G_{t, g} .
\end{aligned}
$$

Eq. (9) indicates that the tasks completed in the same enterprise only need to meet the predecessor task constraints of intra-enterprise production. Eq. (10) indicates that the predecessor constraints and the crossenterprise transportation time constraints need to be met when tasks are transferred across enterprises, and the subsequent constraints are the same.

$$
\sum_{g \in G r T_{t}, b \in \text { Batch }_{g, t}} q t y P L_{b, g, t}=q t y J_{j T_{t}}, t \in T A S K
$$

$$
\begin{aligned}
& \sum_{g \in G r T_{t}, b \in B a t c h_{g, t}} t s P L_{b, g, t} \times n s P L_{b, g, t}= \\
& =q t y J_{j T_{t}} \times u t P C_{p c T_{t}}, t \in T A S K
\end{aligned}
$$

Eq. (11) indicates that the total production quantity of each batch of task $t$ on the professional unit is the total production quantity of the task. Eq. (12) indicates that the total man-hours required for each task is equal to the sum of the man-hours for all batches of the task in each professional unit.

\subsubsection{Model Solving}

The production planning problem in industrial applications does not demand an optimal solution, but focuses on solving a sufficiently optimal feasible solution. This paper mainly uses the branch cutting algorithm framework [22-23] to solve the problem, and the algorithm pseudo code is as follows:

set $X=<x_{1}, \ldots, x_{n}>$.

Use constraints to cut each $x$ value range until it cannot be cut;

There are undetermined variables in while $X$ :

Choose an undetermined variable $x$ in $X$;

Use constrained cutting $x$ range;

The if $x$ value range is empty:

Backtracking

else:

Choose a value $v$ from the range of $x$ and assign it to $x$; end while.

The collaborative production tasks between enterprises need to be split into multiple enterprises and professional units. The solution strategy in this paper first determines the professional units that can be undertaken by the task, and then determines the start time of the task. Because multiple companies may undertake the production of the same part, it is also necessary to determine the number of parts produced by each company's professional unit, as well as the daily production hours and days for each batch. Finally, the successor company of the task and the end time of the task are determined.

$$
\min \#\left\{\Delta\left\{\# V T_{t}\right\}\right\}, t \in T A S K
$$

$\min \#\left\{\Delta\left\{\# G r T_{t}\right\}\right\}, t \in T A S K$

$\max p t O_{o J T_{t}}, t \in T A S K$

$\# G r T_{t}=?(\leftarrow)$

$\max t m T G_{g, t}, g \in \Delta G r T_{t}$

$\min \#\left\{\Delta\left\{\# \operatorname{tmT} G_{g, t}\right\}\right\}, g \in \Delta G r T_{t}$

$\min u p G_{g}, g \in \Delta G r T_{t}$

where, \# represents the number of elements in the set, and $\Delta$ represents the set of undetermined elements. Eq. (13) to Eq. (15) respectively represent the task $t$ with the least undetermined number of optional companies, the least undetermined number of optional professional units, and the highest order priority of the task. Eq. (16) represents the number of professional units that can be undertaken for the task t from large to small. Eq. (17) to Eq. (19) select the professional unit $g$ with the largest upper bound of production time, the smallest production time span, and the smallest production unit price. Eq. (20) represents the search for professional unit $g$.

\section{EXPERIMENT AND RESULTS 4.1 Application Case}

On the basis of technical research, the industrial Internet cloud manufacturing service platform named INDICS was built. The platform focuses on productive services and forms an open and collaborative cloud cooperation ecosystem around the entire life cycle of manufacturing. Production enterprises can rely on the platform to break through corporate resource constraints and build a virtual enterprise circle with upstream and downstream cooperative enterprises. Based on the platform to carry out collaborative procurement, design, production, service and other businesses, the efficiency of manufacturing resource scheduling between enterprises can be improved.

In order to integrate manufacturing resources into the INDICS platform, industrial intelligent gateway products were developed. The industrial intelligent gateway products are deployed in the enterprise, and the manufacturing resources and manufacturing capacity data in the enterprise IT system, OT system and equipment can be mapped and configured according to the data specification of the platform, and transmitted to the INDICS platform.

The case selects a vehicle hydraulic component assembly manufacturer V0 registered on the INDICS platform, and cooperates with three other component manufacturers to complete the production of four products including hydraulic leveling cylinders, pressure valves, flow valves, and hydraulic pumps. Among them, the hydraulic leveling cylinder (Fig. 7) is the most important executive element. It converts hydraulic energy into mechanical energy and cooperates with other parts to 
complete the predetermined leveling action. The hydraulic leveling cylinder is mainly composed of 37 parts such as outer cylinder tube, inner cylinder tube, upper cylinder cover, piston rod, piston, support plate, ball head gland, ball head, guide sleeve, snap ring, and pressure plate. Its production process information is shown in Tab. 2 .

Table 2 Summary of product process

\begin{tabular}{|c|c|c|c|c|c|}
\hline $\begin{array}{c}\text { Process } \\
\text { number }\end{array}$ & Process name & BOM & $\begin{array}{c}\text { Resource } \\
\text { Type }\end{array}$ & $\begin{array}{c}\text { Working } \\
\text { hours }\end{array}$ & Order \\
\hline 010101 & $\begin{array}{c}\text { Cylinder } \\
\text { assembly }\end{array}$ & $\begin{array}{c}\text { Leveling } \\
\text { cylinder }\end{array}$ & $\begin{array}{c}\text { Cylinder } \\
\text { assembly }\end{array}$ & 18 & 1 \\
\hline 010102 & $\begin{array}{c}\text { Cylinder } \\
\text { experiment }\end{array}$ & $\begin{array}{c}\text { Leveling } \\
\text { cylinder }\end{array}$ & $\begin{array}{c}\text { Cylinder } \\
\text { experiment }\end{array}$ & 36 & 2 \\
\hline 010201 & $\begin{array}{c}\text { Rough } \\
\text { machining of } \\
\text { outer cylinder }\end{array}$ & $\begin{array}{c}\text { Outer } \\
\text { cylinder }\end{array}$ & $\begin{array}{c}\text { Ordinary } \\
\text { machine plus }\end{array}$ & 4 & 1 \\
\hline 010203 & $\begin{array}{c}\text { Finishing of } \\
\text { outer cylinder }\end{array}$ & $\begin{array}{c}\text { Outer } \\
\text { cylinder } \\
\text { treatment of } \\
\text { outer cylinder }\end{array}$ & $\begin{array}{c}\text { Precision } \\
\text { machining }\end{array}$ & 8 & 2 \\
\hline 010204 & $\begin{array}{c}\text { Surface } \\
\text { treatment of } \\
\text { outer cylinder }\end{array}$ & $\begin{array}{c}\text { Outer } \\
\text { cylinder }\end{array}$ & $\begin{array}{c}\text { Heat } \\
\text { treatment } \\
\text { treatment }\end{array}$ & 4 & 3 \\
\hline$\ldots 10301$ & $\begin{array}{c}\text { Rough } \\
\text { machining of } \\
\text { inner cylinder }\end{array}$ & $\begin{array}{c}\text { Inner } \\
\text { cylinder }\end{array}$ & $\begin{array}{c}\text { Ordinary } \\
\text { machine plus }\end{array}$ & 4 & 1 \\
\hline$\ldots$ & $\ldots$ & $\ldots$ & $\ldots$ & 4 \\
\hline
\end{tabular}

Tab. 3 shows all the order information received by the company $\mathrm{V} 0$ from the INDICS platform in a certain period of time. After the company $\mathrm{V} 0$ receives the order, when formulating the overall assembly plan of the company, it needs to take the production plan of the cooperative supporting parts company into overall consideration to ensure the feasibility of the company's manufacturing plan. Tab. 4 shows the professional units and resource types that each enterprise participates in collaborative production.

\begin{tabular}{|c|c|c|c|c|c|c|}
\hline \multicolumn{7}{|c|}{ Table 3 The list of orders } \\
\hline No. & Products & Quantity & $\begin{array}{c}\text { Earliest } \\
\text { start date }\end{array}$ & $\begin{array}{c}\text { Delivery } \\
\text { date }\end{array}$ & Artifact & Process \\
\hline 1 & $\begin{array}{c}\text { Leveling } \\
\text { cylinder }\end{array}$ & 100 & $\begin{array}{c}2020-05- \\
25\end{array}$ & $\begin{array}{c}2020-06- \\
19\end{array}$ & 37 & 51 \\
\hline 2 & $\begin{array}{c}\text { Pressure } \\
\text { valve }\end{array}$ & 100 & $\begin{array}{c}2020-05- \\
25\end{array}$ & $\begin{array}{c}2021-06- \\
22\end{array}$ & 13 & 21 \\
\hline 3 & $\begin{array}{c}\text { Flow } \\
\text { valve }\end{array}$ & 100 & $\begin{array}{c}2020-05- \\
25\end{array}$ & $\begin{array}{c}2021-06- \\
22\end{array}$ & 12 & 18 \\
\hline 4 & $\begin{array}{c}\text { Hydraulic } \\
\text { pump }\end{array}$ & 100 & $\begin{array}{c}2020-05- \\
25\end{array}$ & $\begin{array}{c}2021-06- \\
29\end{array}$ & 33 & 46 \\
\hline 5 & $\begin{array}{c}\text { Flow } \\
\text { valve }\end{array}$ & 100 & $\begin{array}{c}2020-05- \\
25\end{array}$ & $\begin{array}{c}2021-06- \\
30\end{array}$ & 12 & 18 \\
\hline 6 & $\begin{array}{c}\text { Leveling } \\
\text { cylinder }\end{array}$ & 100 & $\begin{array}{c}2020-05- \\
25\end{array}$ & $\begin{array}{c}2020-07- \\
03\end{array}$ & 37 & 51 \\
\hline 7 & $\begin{array}{c}\text { Leveling } \\
\text { cylinder }\end{array}$ & 100 & $\begin{array}{c}2020-05- \\
25\end{array}$ & $\begin{array}{c}2020-07- \\
08\end{array}$ & 37 & 51 \\
\hline 8 & $\begin{array}{c}\text { Hydraulic } \\
\text { pump }\end{array}$ & 100 & $\begin{array}{c}2020-05- \\
25\end{array}$ & $\begin{array}{c}2021-07- \\
09\end{array}$ & 33 & 46 \\
\hline 9 & $\begin{array}{c}\text { Flow } \\
\text { valve }\end{array}$ & 100 & $\begin{array}{c}2020-05- \\
25\end{array}$ & $\begin{array}{c}2021-07- \\
10\end{array}$ & 12 & 18 \\
\hline 10 & $\begin{array}{c}\text { Pressure } \\
\text { valve }\end{array}$ & 100 & $\begin{array}{c}2020-05- \\
25\end{array}$ & $\begin{array}{c}2021-07- \\
10\end{array}$ & 13 & 21 \\
\hline & & & & & 12 \\
\hline
\end{tabular}

According to the data in Tab. 2 to Tab. 4, relying on the INDICS platform to use the resource scheduling mechanism in Section 3.4, the collaborative production resource scheduling of the four companies is completed. The resource scheduling mechanism model and algorithm are implemented through Natural Constraint Language (NCL), and the problem is solved based on the POEM3.0 optimized computing component (deployed on the INDICS platform). Under the premise of ensuring on-time delivery, it can provide a resource scheduling strategy with low cost and short span for demanding enterprises.

Table 4 Summary of resources

\begin{tabular}{|c|c|c|c|}
\hline No. & Professional Unit & Resource Type & $\begin{array}{c}\text { Affiliated } \\
\text { company }\end{array}$ \\
\hline 1 & Cylinder assembly unit & Cylinder assembly & $\mathrm{V}_{0}$ \\
\hline 2 & Cylinder experiment unit & Cylinder experiment & $\mathrm{V}_{0}$ \\
\hline 3 & Machine plus unit & Ordinary machine plus & $\mathrm{V}_{1}$ \\
\hline 4 & Precision machining unit & Precision machining & $\mathrm{V}_{1}$ \\
\hline 5 & Heat treatment unit & Heat treatment & $\mathrm{V}_{1}$ \\
\hline 6 & Surface treatment unit & Surface treatment & $\mathrm{V}_{1}$ \\
\hline$\ldots$ & $\ldots$ & $\ldots$ & $\ldots$ \\
\hline 21 & Special cutting unit & $\begin{array}{c}\text { Wire cutting } \\
\text { processing }\end{array}$ & $\mathrm{V}_{3}$ \\
\hline
\end{tabular}

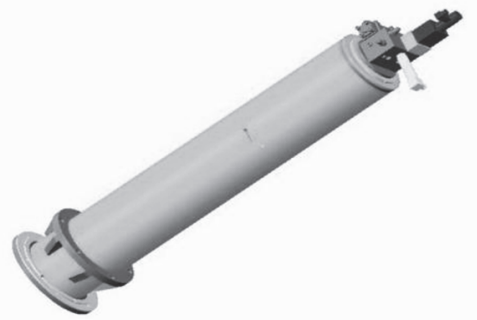

Figure 7 The 3D model drawing of leveling cylinder in hydraulic system

\subsection{Results and Discussion}

According to the optimization goals proposed in Section 3.4.2, the results of the case were discussed and analyzed from the three aspects of small order delivery delay, small production span and low production cost of the enterprise.

Fig. 8 shows the difference between the production completion time of each order and the delivery time required by the order. It can be seen from Fig. 8 that all orders can be delivered in accordance with the time required by the order, which can achieve the goal of small tardiness, and can provide data support for collaborative production between enterprises.

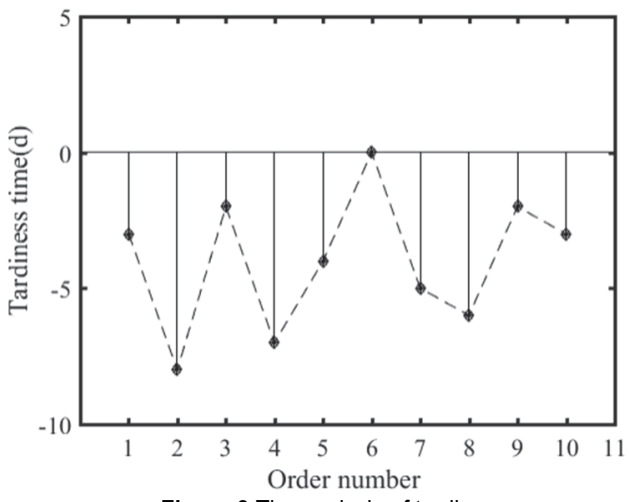

Figure 8 The analysis of tardiness

From the perspective of production span, Fig. 9 shows the average daily utilization rate of each professional unit. It can be found that the average daily utilization rate of professional units has reached more than $60 \%$. The high daily utilization rate of professional units of an enterprise can reflect the small production span under the same 
production volume, which verifies that the small span is in the optimization goal.

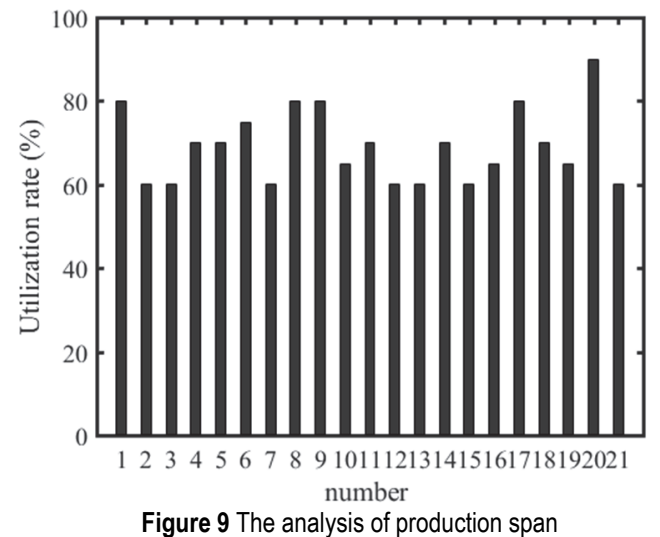

From the perspective of production costs, suppliers V2 and $\mathrm{V} 3$ undertake the production tasks of leveling cylinder parts, and supplier V2's quotation is lower than that of V3. Fig. 10 shows the summary information of the total working hours of the four types of professional units undertaken by the suppliers V2 and V3 to undertake the production tasks of leveling cylinder parts. Where, Unit 1 is ordinary machine plus professional unit, Unit 2 is precision machine plus professional unit, Unit 3 is heat treatment professional unit, and Unit 4 is surface treatment professional unit. Enterprise V2 has undertaken more production tasks and also verified the low cost optimization goal. Therefore, the manufacturing resource scheduling mechanism proposed in this paper can allocate production quantities for outsourcing enterprises more economically and reduce overall production costs.

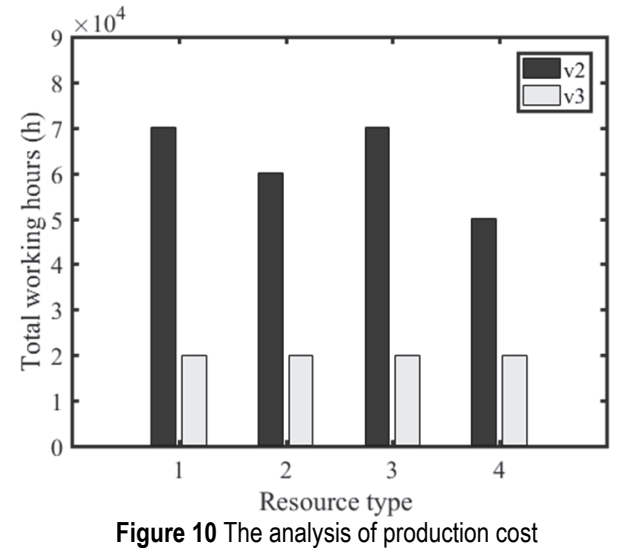

\section{CONCLUSION}

In this paper, based on metadata and ontology modeling methods, a standardized model description of manufacturing resources is realized. Based on the hybrid ensemble planning method, considering multiple constraints, a demand-oriented order-oriented resource collaborative scheduling mechanism between enterprises is proposed, which is verified in conjunction with corresponding calculation examples. It can provide an application reference for the collaborative scheduling of virtual enterprise circle manufacturing resources based on the cloud manufacturing service platform. After receiving the order, the company can quickly understand the overall situation of the resource allocation including the supplier, timely discover and solve the resource bottleneck in the production, and improve the production efficiency.

In the future research, the model and scheduling mechanism proposed in this paper can be combined with the study of inter-enterprise logistics to improve the efficiency of inter-enterprise resource collaboration.

\section{Acknowledgement}

The study was supported by the National Key R\&D Program of China (No.2020YFB1710500).

\section{REFERENCES}

[1] Potts, C. N. \& Strusevich, V. A. (2009). Fifty years of scheduling: a survey of milestones. Journal of the Operational Research Society, 60(1), S41-S68. https://doi.org/10.1057/jors.2009.2

[2] Li, B. H., Hou, B. C., Yu, W. T., Xiao-bing, L., \& Chun-wei, Y. (2017). Applications of artificial intelligence in intelligent manufacturing: a review. Frontiers of Information Technology \& Electronic Engineering, 18(1), 86-96. https://doi.org/10.1631/FITEE.1601885

[3] Siderska, J. \& Jadaan, K. (2018). Cloud manufacturing: a service-oriented manufacturing paradigm. A review paper. Engineering Management in Production and Services, 10(1) 22-31. https://doi.org/10.1515/emj-2018-0002

[4] Li, B. H., Zhang, L.,Wang, S. L., Tao, F., Cao, J. W., Jiang, X. D., Song, X., \& Chai, X. D. (2010). Cloud manufacturing: A new service-oriented networked manufacturing model.Comput. Integr. Manuf. Syst., 16(1), 1-7. Retrieved from: http://cims-journal.cn/EN/abstract/article_2516.shtml

[5] Liu, Y. K., Wang, L. H., Wang, X. V., Xun, X., \& Pingyu, J. (2019). Cloud manufacturing: key issues and future perspectives. International Journal of Computer Integrated Manufacturing, 32(9), 858-874. https://doi.org/10.1080/0951192X.2019.1639217

[6] Thekinen, J. \& Panchal, J. H. (2017). Resource allocation in cloud-based design and manufacturing: A mechanism design approach. Journal of Manufacturing Systems, 43(2), 327338. https://doi.org/10.1016/j.jmsy.2016.08.005

[7] Wang, X. V. \& Xu, X. W. (2013). An interoperable solution for cloud manufacturing. Robotics and Computer-Integrated Manufacturing, 29(4), 232-247. https://doi.org/10.1016/j.rcim.2013.01.005

[8] Zhang, L., Luo, Y. L., Tao, F., Ren, L., \& Guo, H. (2010). Key technologies for the construction of manufacturing cloud. Computer Integrated Manufacturing Systems, 16(11), 2510-2520. https://doi.org/10.3724/SP.J.1238.2010.00585

[9] Wang, S., Chen, G., Kang, L., \& Li, Q. (2012). Information model of cloud manufacturing resource based on semantic web. International Journal of Digital Content Technology and Its Applications, 6(19), 339-346. https://doi.org/10.4156/jdcta.vol6.issue19.42

[10] Wang, Y., Dai, Z., Zhang, W., Zhang, S., Xu, Y., \& Chen, Q. (2018). Urgent task-aware cloud manufacturing service composition using two-stage biogeography-based optimisation. International Journal of Computer Integrated Manufacturing, 31(10), 1034-1047. https://doi.org/10.1080/0951192X.2018.1493230

[11] Wang, Y., Ma, H. S., Yang, J. H., \& Wang, K. S. (2017) Industry 4.0:a way from mass customization to mass personalization production. The International Journal of Advanced Manufacturing Technology, 5(4), 311-320. https://doi.org/10.1007/s40436-017-0204-7

[12] Zhang, Y., Zhang, G., Liu, Y., \& Hu, D. (2017). Research on services encapsulation and virtualization access model of 
machine for cloud manufacturing. J Intell Manuf, 28, 11091123. https://doi.org/10.1007/s10845-015-1064-2

[13] Yuan, M. H. , Zhou, Z., Cai, X. X., Sun. C., \& Gu, W. (2020). Service composition model and method in cloud manufacturing. Robotics and Computer-Integrated Manufacturing, 61. https://doi.org/10.1016/j.rcim.2019.101840

[14] Wu, D. , Greer, M. J., Rosen, D. W., \& Dirk, S. (2013). Cloud manufacturing: Strategic vision and state-of-the-art. Journal of Manufacturing Systems, 32(4), 564-579. https://doi.org/ 10.1016/j.jmsy.2013.04.008

[15] Peng, C. \& Meng, Y. J. (2016). Empirical study of manufacturing enterprise collaboration network: Formation and characteristics. Robotics and Computer-Integrated Manufacturing, 42, 49-62. https://doi.org/10.1016/j.rcim.2016.05.005

[16] Tang, H. , Li, D., Wang, S., \& Dong, Z. (2018). CASOA: An architecture for agent based manufacturing system in the context of industry 4.0. IEEE Access, 6, 12746-12754. https://doi.org/ 10.1109/ACCESS.2017.2758160

[17] Arkat, J. \& Ghahve, H. (2014). Scheduling of virtual manufacturing cells with outsourcing allowed. International Journal of Computer Integrated Manufacturing, 27. https://doi.org/10.1080/0951192X.2013.874581

[18] Kesen, S. E., Das, S. K., \& Gungor, Z. A. (2010). A mixed integer programming formulation for scheduling of virtual manufacturing cells(VMCs). International Journal of Advanced Manufacturing Technology, 47(5-8), 665-678. https://doi.org/10.1007/s00170-009-2231-4

[19] Zhao, C., Wang, L. H., \& Zhang, X. S. (2020). Service agent networks in cloud manufacturing: Modeling and evaluation based on set-pair analysis. Robotics and ComputerIntegrated Manufacturing, 65, 1-9. https://doi.org/10.1016/j.rcim.2020.101970

[20] Li, Y. \& Yao, X. (2018). Cloud manufacturing service composition and formal verification based on extended process calculus. Advances in Mechanical Engineering. https://doi.org/10.1177/1687814018781287

[21] Alinani, K., Liu, D., \& Zhou, D. (2020). Service composition and optimal selection in cloud manufacturing: State-of-theart and research challenges. IEEE Access, 8, 223988-224005, 2020. https://doi.org/10.1109/ACCESS.2020.3045008

[22] Zheng, L. B., Gu, J. N., \& Dai, Y. R. (2009). Modeling of Manufacturing Resources Based on Ontology. Mach. Des. Res., 25(5), 61-63. https://doi.org/10.1061/41039(345)45

[23] Sarkar, A. (2019). Ontology model for process level capabilities of manufacturing resources. Procedia Manufacturing, 39, 1889-1898. https://doi.org/10.1016/j.promfg.2020.01.244

[24] Zhu, L. N., Li, P. H., \& Shen, G. J. (2020). A novel service composition algorithm for cloud-based manufacturing environment. IEEE Access, 8, 39148-39164. https://doi.org/10.1109/ACCESS.2020.2976164
[25] Wang, L., Guo, S. , Li, X., Du, B., \& Xu, W. (2018). Distributed manufacturing resource selection strategy in cloud manufacturing". Int. J. Adv. Manuf. Technol., 94(9), 3375-3388. https://doi.org/10.1007/s00170-016-9866-8

[26] Li, X., Zhuang, P., \& Yin, C. (2019). A metadata based manufacturing resource ontology modeling in cloud manufacturing systems". Journal of ambient intelligence and humanized computing, 10(3), 1039-1047. https://doi.org/10.1007/s12652-018-0964-3

[27] Graham, R. L., Lawlerel, L., Lenstra, J. K., Rinnooy, A. H. G. (1977). Optimization and approximation in deterministic sequencing and scheduling: a survey. Annals of Discrete Mathematics, 5(1), 287-326. https://doi.org/10.1016/S0167-5060(08)70356-X

[28] Zhou J. Y. (2000). Introduction of the constraint language NCL. Journal of Logic Programming, 45(1/2/3), 71-103. https://doi.org/10.1016/S0743-1066(99)00063-1

\section{Contact information:}

Wei SHI, PhD candidate

College of Mechanical and Electrical Engineering, Nanjing University of Aeronautics and Astronautics,

Nanjing, P.R. China

Beijing Aerospace Smart Manufacturing Technology of Development Co., Ltd.,

Beijing, P.R. China

E-mail: shiwei142@163.com

Dunbing TANG, PhD, Professor

(Corresponding author)

College of Mechanical and Electrical Engineering, Nanjing University of

Aeronautics and Astronautics,

Nanjing, P.R. China

E-mail: d.tang@nuaa.edu.cn

Ping ZOU, PhD candidate

Beijing Aerospace Smart Manufacturing Technology of Development Co., Ltd., Beijing, P.R. China

E-mail: zouping@casicloud.cn 